\title{
ENSINO DE LÍNGUA DE SINAIS: ASPECTOS VARIACIONAIS FONOLÓGICOS DA LÍNGUA BRASILEIRA DE SINAIS
}

\author{
SIGN LANGUAGE TEACHING: PHONOLOGICAL VARIATIONAL ASPECTS \\ OF LIBRAS, BRAZILIAN SIGN LANGUAGE
}

\author{
Kátia Michaele Conserva Albuquerque \\ Evangelina Brito Fariai
}

RESUMO: Com a implementação de cursos de Graduação em Libras no país, é natural uma preocupação maior com a descrição dos elementos que compõem essa língua para uma melhor relação de ensino/aprendizado. Nesse campo, a sociolinguística propiciou grandes mudanças no ensino de língua e isso abrange a língua de Sinais. A noção de heterogeneidade da língua foi proposta por Labov (2008) baseando-se no estudo da estrutura interna e na evolução da língua em uso por determinada comunidade linguística. Este artigo tem por objetivo descrever os componentes fonológicos variacionais na língua brasileira de sinais de usuários das comunidades de fala de João Pessoa e Recife, para contribuir com estudos sobre ensino e variação linguística. Para a coleta de dados foi utilizado o banco de dados da pesquisa "A língua brasileira de sinais no Nordeste: as variantes de João Pessoa e Recife". O referente estudo foi uma parceria entre a Universidade Federal da Paraíba (UFPB), a Universidade Católica de Pernambuco (UNICAP) e o Instituto do Patrimônio Histórico e Artístico Nacional (IPHAN). A metodologia obedeceu as seguintes etapas: (1) selecionar duas categorias semânticas da lista SWADESH; (2) identificar os sinais que apresentam variação fonológica; (3) descrever as unidades fonológicas variacionais; (4) especificar os parâmetros que apresentaram variação fonológica. Para a descrição das variações fonológicas foi utilizado o software para transcrição Eudico Linguistic Annotator (ELAN). As análises dos dados mostram que as diferenças são marcadas por aspectos culturais da região, conectados à experiência de cada comunidade e podem ser identificadas pela variação dos parâmetros fonológicos das línguas de sinais.

PALAVRAS-CHAVE: Variação fonológica. Libras. Ensino.

ABSTRACT: The sociolinguistics led the look on the deaf people, as speakers of a visual language, the sign language. Among the research in the area, the linguistic variation have been constituted as an object of research across the country. The heterogeneity of the language was proposed by Labov (2008) based on the study of the internal structure and evolution of the language in use by a particular linguistic community. This research aims to investigate and describe this process of linguistic variation, more specific, the variational phonological components in sign language speakers of the Joao Pessoa and Recife communities. To collect the data

\footnotetext{
' Instituto . E-mail: endereço eletrônico de contato. 
we used the database of the research called: "The Brazilian sign language in the northeast: the variants of Joao Pessoa and Recife." The referent study was a partnership between the Federal University of Paraíba (UFPB), the Catholic University of Pernambuco (UNICAP) and the Institute of Historical and Artistic Heritage (IPHAN). The methodology followed the following steps: (1) To select two semantic categories of the Swadesh list, (2) To identify the signals that show phonological variation. (3) To describe the variational phonological units, (4) To specify the types of phonological variation. For a description of the phonological variations, was used a software to transcribe called Eudico Linguistic Annotator (ELAN). The data analysis resulted in a descriptive framework of phonological parameters that had higher rates of variation of phonological LIBRAS used by speakers of João Pessoa and Recife.

KEYWORDS: Sociolinguistics. Phonological variation. LIBRAS.

Submetido em: 30 ago. 2017

Aprovado em: 11 dez. 2018

\section{A língua de sinais e a variação}

A linguagem é compreendida como uma capacidade humana de comunicação, proporcionando ao homem competência para uso, produção e compreensão dos signos e se estabelece por processos fonológicos, morfológicos, sintáticos, semânticos e pragmáticos da língua. A interação entre sistema linguístico e conteúdo conceptual resulta na formação da palavra, fruto da apreensão e da experiência de mundo. O conteúdo conceptual aliado à experiência de mundo permite à pessoa surda construir sua relação com o meio de maneira visual, denominado por alguns autores como experiência visual. Farias (apud STROBEL, 2008, p. 37) afirma que conhecer o mundo pela visão significa desenvolver um código visual com o qual os surdos associam significado e significante a partir de informações visuais que extraem do meio.

A língua de sinais caracteriza-se pela modalidade visual-espacial e, semelhante às línguas orais, possui elementos fonológicos, morfológicos, sintáticos, semânticos baseados no uso e na experiência social. O atributo visual da língua de sinais constitui um modo de organização dos sentidos aliado ao contexto sociocultural. Visto que a conceptualização da linguagem recebe 
contribuição do social, pressupõe-se que as línguas de sinais também sofrem influências sociolinguísticas (origem geográfica, sexo, faixa etária, nível econômico, escolaridade). Essas diferenças são marcadas por aspectos culturais da região e podem ser identificadas pela variação dos parâmetros fonológicos das línguas de sinais.

Os estudos sobre as línguas de sinais não dispensam a análise da relação entre o sociocultural e a língua. Pesquisas que investigam essa relação identificam o emprego de diferentes aspectos fonológicos, constatando a variação linguística. O mesmo fenômeno acontece com as comunidades linguísticas usuárias das línguas de sinais.

Compreendendo que a formação do signo linguístico ocorre por meio da interação cognitiva e dos elementos socioculturais, Labov (2008) afirma que a língua não existe fora de um contexto social. Histórias sobre crianças que cresceram isoladas comprovam a inexistência do uso da língua, visto que não participam de relações interpessoais nas quais se torna necessário exprimir desejos, necessidades e ideias. Portanto, a sociolinguística ou sociologia da linguagem ${ }^{1}$, assim denominada por Labov, investiga os fenômenos linguísticos associados aos fatores sociais. O social reflete os vários modos de expressão de um grupo social ou comunidade linguística, no qual as expressões e signos linguísticos utilizados estão conectados à experiência sociocultural.

Diversos fatores são considerados quando estudamos a língua partindo do uso de situações reais: o espaço geográfico ao qual os falantes pertencem; a fala característica das diferentes regiões brasileiras etc.; a classe socioeconômica; o nível de formação educacional que influencia as preferências quanto à leitura e à escrita, a idade, o sexo e o comportamento linguístico nas redes sociais. Tais aspectos ratificam a heterogeneidade da língua nos espaços de convivência social.

Portanto, a variedade de signos linguísticos utilizados por esses grupos evidenciam o conceito de "langue" apresentado por Saussure (1962 apud LABOV, 2008, p. 217): langue "est la partie sociale du langage... elle n'existe

\footnotetext{
${ }^{1}$ Labov considera equivocado atribuir o termo sociolinguística a pesquisas que investigam a língua numa perspectiva social, visto que é considerada como uma forma de comportamento social. (LABOV, 2008, p. 215).
} 
qu'en vertu d'une sorte de contrat passé entre les membres de lá communauté" [é a parte social da linguagem... ela não existe fora de um contrato estabelecido entre os membros da comunidade]. Labov se opõe a Saussure problematizando a heterogeneidade nas comunidades linguísticas. Para ele, o discurso sustentado pela linguística de que as variações consistiam em desvios da língua padrão foi eliminado pelo reconhecimento da variedade como resultado de fatores linguísticos fundamentais (LABOV, 1966 apud SOUSA; SEGALA, 2009). A teoria sobre variação linguística proposta por Labov tem como foco o estudo da estrutura e evolução de determinada língua falada por uma comunidade linguística inserida em um contexto social (LABOV, 2008). Sua proposta teórica foi organizada metodologicamente a fim de analisar de que forma as estruturas internas de uma determinada língua sofrem modificações devido a fatores externos durante o seu uso.

As pesquisas sociolinguísticas devem considerar os fatos relacionados ao uso da língua e os fatores históricos que contribuem para a mudança e variação da língua. Este aporte teórico investiga a intrínseca relação entre língua e sociedade e se preocupa em estudar os fenômenos linguísticos que ocorrem em uma determinada comunidade de fala e que podem sofrer variação e/ou mudança linguística.

\footnotetext{
Um modelo de língua que acomode os fatos do uso variável e seus determinantes sociais e estilísticos não só leva a descrições mais adequadas da competência linguística, mas também suscita naturalmente uma teoria da mudança linguística que ultrapassa os estéreis paradoxos contra os quais a linguística histórica vem lutando há mais de meio século (WEINREICH, LABOV, HERZOG, 2006, p. 34).
}

Essa concepção sobre a língua embasou o programa de pesquisa com o intuito de explicar os fenômenos de variação linguística, considerando influências histórico-sociais, os traços linguísticos, as mudanças fonológicas nas comunidades de fala. Estes dados empíricos formam a análise inicial para coleta de dados e um olhar mais específico sobre os elementos variacionais. Busca-se compreender a partir de dados extralinguísticos quais as variáveis determinantes para as modificações fonológicas.

O enlace de variáveis sociais e aspectos fonológicos permite ao pesquisador organizar os dados que serão analisados. A análise sobre os 
aspectos extralinguísticos envolvem a língua em uso por comunidades de fala. Na proposta sociolinguística, o objeto primário de estudo não é o idioleto, mas a comunidade de fala, pois as características coletivas são unidades de medida relevantes e se estabelecem antes da fala.

O processo de mudança linguística acontece em três estágios: na origem; em que há o uso restrito de variantes a algumas pessoas; na propagação, esta variante é adotada por um número amplo de falantes e passa a contrastar com a forma mais antiga; e no término, a mudança torna-se regular pela eliminação das variantes concorrentes (STUTEVANT, 1947 apud LABOV, 2008 [1972]).

As variantes são formas alternativas que constituem um fenômeno variável, denominada como variáveis dependentes ou independentes. A primeira classificação refere-se àquelas empregadas mediante influências de ordem social. A segunda corresponde as que são constituídas por uma ordem estrutural e são subdivididas em variáveis internas e externas.

As variáveis internas estruturais concentram os fatores de natureza fonológica, morfológica, sintática, semântica, discursivas e lexicais. As variáveis externas à língua reúnem fatores intrínsecos ao sujeito, ao social e contextual.

O norteamento deste trabalho segue a perspectiva laboviana das línguas orais auditivas como parâmetro dos estudos das línguas de sinais, compreendendo que o surgimento de signos linguísticos, bem como a identificação das variações é possível devido à vida social de cada comunidade linguística.

A emergência das línguas sinalizadas está associada a vários fatores, dentre eles a união de línguas sinalizadas e de sinais caseiros, denominados como língua de sinais primária, num processo de pidgin² tornando-se uma língua crioula ${ }^{3}$. Também houve empréstimos linguísticos das línguas orais para formar o alfabeto (SOUSA; SEGALA, 2009, p. 28). Considerando a língua como um sistema de relações opositivas, as diferenças fonológicas apresentam funções contrastivas possíveis de serem distinguidas com êxito. Nas décadas de 60 e 70,

\footnotetext{
2 Também denominada língua de contato. É criada a partir de uma mistura de línguas com o objetivo de servir como meio de comunicação em situações migratórias que reúnem usuários de idiomas diferentes que precisam se comunicar.

${ }^{3}$ A língua crioula é derivada de um pidgin sendo possível distingui-la observando três aspectos: - processo de formação, a sua relação com uma língua de prestígio, particularidades gramaticais.
} 
quando Stokoe; Klima; Bellugi identificaram os traços fonológicos, houve uma compreensão desses parâmetros enquanto unidades distintivas.

Estes autores iniciaram os estudos sobre a American Sign Language $(A S L)$, identificaram os parâmetros fonológicos que compõem o signo linguístico, dentre eles, a configuração de mãos, considerada como imagem acústica ${ }^{4}$ ou sensorial. Embora os termos fonologia e imagem acústica sejam estranhamente utilizados para o estudo e descrição das unidades mínimas que compõem a língua de sinais, referimo-nos ao fato de que a língua de sinais, em seu aspecto visual, é formada por um grupo finito de unidades, que se combinam de maneira ilimitada, formando morfemas e signos linguísticos (SANDLER; LILLO-MARTIN, 2006 apud STUMPF, 2012).

O uso do termo "fonológico" sofreu um processo de transição por se tratar de uma língua visuoespacial em que as mãos são usadas para articular os sinais. Em 1960, Stokoe adotou os termos "quirema" e "quirologia" ao invés de fonema. Tais palavras são derivadas do grego quiro, que significa "mão". Posteriormente, em 1978, o autor retomou os termos fonema e fonologia aplicando seus significados à linguística visual-espacial, visto que a língua de sinais compartilha princípios linguísticos semelhantes às línguas orais, apesar das diferenças de modalidade ${ }^{5}$.

A divisão dos parâmetros na língua de sinais americana (ASL) permitiu a análise e identificação dos traços distintivos. De modo semelhante, a distinção dos parâmetros proporcionou a análise contrastiva das línguas de sinais em vários países, fato que comprova a influência da cultura para a criação dos símbolos linguísticos.

Os estudos sobre variação linguística consideram o indivíduo inserido em sua comunidade de fala, sendo esta o locus dos referidos estudos. Em relação às línguas de sinais encontramos variações linguísticas da mesma maneira que nas línguas orais. Essas variações existem entre as línguas de sinais de diversas regiões. As variações sociolinguísticas das línguas de sinais não estão contidas

\footnotetext{
${ }^{4}$ É importante elucidar que o conceito "acústico" refere-se à imagem produzida/percebida pelos sentidos. Portanto, neste trabalho em que abordamos os aspectos fonológicos da língua de sinais, adotamos o conceito de imagem sensorial, visto que os parâmetros (elementos que compõem a formação do sinal) são percebidos visualmente.

${ }^{5}$ Sobre isso, ver os estudos de Klima; Bellugi (1979); Wilbur (1987); Hulst (1993) apud Quadros; Karnopp 2004, p. 48.
} 
apenas no léxico, mas também, e principalmente, nos aspectos morfológicos e semânticos. A maneira como as pessoas de regiões diferentes enxergam 0 mundo, ainda que num mesmo país, difere em muito. A bagagem sociocultural de cada indivíduo e sociedade interferem na elaboração do signo, seja na criação do significante ou na produção do significado. Dessa forma, reconhecemos as diferenças de vocabulário, expressões idiomáticas, gírias locais, dialetos, polissemias e até mesmo de sotaque.

As relações sociais e a vida nas comunidades de fala constituem o cenário sob o qual a língua é produzida. Portanto, a posição teórica abordada neste trabalho elucida o embasamento científico sobre o qual construímos nossas discussões e análises do corpus coletado. Partindo desta compreensão, visamos identificar aspectos variacionais fonológicos da Libras, estabelecendo distinção entre os parâmetros variantes nos sinais utilizados em João Pessoa e Recife, considerando nas análises dos dados coletados os aspectos sociais de cada comunidade de fala, como uma contribuição ao ensino da libras. Na próxima seção, trataremos da metodologia adotada e do esclarecimento dos instrumentos para seleção dos dados e análises fonológicas.

\section{Considerações metodológicas}

Este trabalho caracteriza-se como pesquisa documental, pois foi executado pelo acesso e seleção de um banco de dados, para análise e informações adicionais sobre o contexto sociolinguístico, constituindo-se como processo sistemático. Os dados selecionados para análise da variação fonológica pertencem ao banco de dados da pesquisa "A língua brasileira de sinais no Nordeste: as variantes de João Pessoa e Recife", realizado por pesquisadores da Universidade Federal da Paraíba (UFPB) e da Universidade Católica de Pernambuco (UNICAP), com o apoio da Associação Brasileira de Linguística (ABRALIN) e do Instituto do Patrimônio Histórico e Artístico Nacional (IPHAN), denominada neste artigo por pesquisa raiz ${ }^{6}$.

6 A adoção do termo pesquisa raiz segue o modelo utilizado por Isabelle Delgado em sua tese de doutorado em Linguística intitulada "Uma análise estilística da Língua Brasileira de Sinais: variações de seu uso no processo interativo" (2012), que também utilizou o referido banco de dados. 
O delineamento metodológico da pesquisa "A língua brasileira de sinais no Nordeste: as variantes de João Pessoa e Recife" caracteriza-se por tipo qualiquantitativo, de caráter exploratório e analítico. O objetivo principal foi aplicabilidade do Inventário Nacional da Diversidade Linguística em Língua Brasileira de Sinais, em um projeto piloto, no qual foram coletados dados acerca do uso da LIBRAS, como também da variação existente entre as comunidades surdas nos municípios de João Pessoa e de Recife, considerando os estudos variacionais da Língua em tais localidades.

A pesquisa envolveu duzentos e dezesseis sujeitos (cento e oito por cidade), usuários da Língua Brasileira de Sinais, surdos e ouvintes, assim, distribuídos: cinquenta e quatro falantes para cada sexo, nas quatro faixas etárias: 7 a 14 anos (18 falantes); 15 a 35 anos (18 falantes); 35 a 55 anos (18 falantes) e 55 a 75 anos (18 falantes). A escolarização foi uma variável considerada, redistribuindo os sujeitos pelos seguintes critérios: seis falantes sem escolarização; seis contendo 05 a 08 anos de escolarização e seis com mais de 11 anos de escolarização (Ensino Superior). Os dados coletados sobre o uso da Libras nas duas cidades foram organizados conforme Inventário de 200 palavras da lista de SWADESH evidenciando variedades linguísticas nas duas cidades, instrumento que consultamos para selecionar os itens analisados no presente artigo.

No intuito de padronizar o sistema de transcrição de dados da Libras, pesquisadores brasileiros têm utilizado o software Eudico Linguistic Annotator (ELAN). Esse software foi desenvolvido pelo Instituto de Psicolinguística Max Planck, na Holanda, visando à produção de uma base tecnológica para a anotação e análise das línguas de sinais e gestos, mas também apresenta recursos para investigação das línguas orais. Através de suas ferramentas é possível criar, editar, visualizar e fazer notações dos dados. Essa configuração permite registros com fins documentais das línguas estudadas (QUADROS; PIZZIO, 2009). Adotar um software para transcrição de dados confere à pesquisa linguística maior qualidade no tratamento das informações, pois o avanço tecnológico tem permitido análises mais detalhadas da língua nos níveis fonológico, morfológico, sintático e semântico-pragmático. Em especial, os 
dados fonológicos, que são o foco desta pesquisa, no ELAN, ganham uma maior percepção.

\subsection{Tratamento e análise de dados}

As etapas metodológicas foram organizadas em momentos distintos, os quais se destinaram a favorecer a execução da sistematização da pesquisa. $\mathrm{O}$ primeiro momento consistiu em investigar as dez categorias à procura de sinais que apresentassem variação linguística. Após termos uma visão geral do corpus, elegemos as categorias plantas e natureza como recorte para nossa pesquisa, por apresentarem quantidade de signos com variação. No segundo momento, selecionamos os sinais que apresentaram diferenças quando a sua formação. Após a seleção, o terceiro momento consistiu em descrever as variações fonológicas utilizando o ELAN para identificar cada aspecto variacional. Para isso, foram criadas cinco trilhas, cada uma correspondente aos parâmetros fonológicos da Libras: configuração de mão, locação, movimento, orientação e expressão não manual. Cada aspecto foi descrito. O quarto momento consistiu em especificar os tipos de variação, agrupando parâmetros e índice de variação. Finalmente, o quinto momento foi dedicado à análise dos aspectos variacionais. A análise de dados consiste em averiguar as variações fonológicas existentes entre os sinais utilizados por essas comunidades surdas, identificando e classificando as principais diferenças para um ensino mais coerente com seus aspectos estruturais e culturais. Passemos às análises.

\section{Análise dos dados linguísticos}

O ensino sobre variação linguística requer um olhar sobre os contextos da língua em uso. Esta perspectiva da sociolinguística considera a comunidade de falantes, seus costumes e aspectos diacrônicos. Contribui para a comprovação de sua naturalidade, pois estabelece correlação entre dados linguísticos, que sofreram modificações diacrônicas e dos vários dialetos, utilizados pela comunidade de fala (SOUSA; SEGALA, 2009). 
As mudanças diacrônicas resultam de uma mesclagem de sistemas primários (comunicação caseira) e outras línguas de sinais. Essas mudanças foram se sofisticando e se moldando ao sistema linguístico. Por sua vez, as interações linguísticas de uma comunidade constroem a identidade cultural. Por isso, quando estudamos as línguas de sinais analisamos também o papel que elas exercem enquanto veículo das relações sociais e da identidade linguística da comunidade de fala.

Considerando a abordagem teórica laboviana e os aspectos de emergência das línguas de sinais, nossa proposta é analisar as unidades fonológicas que apresentam variação quanto aos parâmetros fonológicos da Libras. Selecionamos 10 sinais do banco de dados da pesquisa raiz, agrupados em duas classes semânticas: plantas e natureza. A primeira categoria reúne palavras da lista SWADESH, dentre as quais selecionamos cinco sinais ${ }^{7}$ que apresentaram variação fonológica: casca, caule, espinho, raiz, semente. $\mathrm{Na}$ segunda categoria selecionamos cinco sinais $^{8}$ que apresentaram variação fonológica: lua, mar, sal, vento, neve. Os referidos termos encontram-se na lista SWADESH. A escolha das classes foi motivada com o intuito de reunir categorias interligadas semanticamente e analisar as construções fonológicas das referidas categorias.

A descrição dos parâmetros fonológicos dos sinais pertencentes às categorias PLANTA e NATUREZA evidencia as variações fonológicas dos sinais usados em João Pessoa e Recife. Ao olhar da sociolinguística, considerando os estudos de Labov, as variações ocorrem porque cada comunidade de fala faz uso de regras linguísticas variáveis, logo, a língua é um sistema variável.

Quando pensamos em variação em Libras, é comum as pessoas imaginarem a análise contrastiva entre sinais do Nordeste e Sudeste. A amostra selecionada aponta que ocorreu um índice de variação considerável nos termos analisados, apesar da proximidade geográfica das cidades João Pessoa e Recife. Percebe-se também que os parâmetros que apresentaram variação fonológica não comprometeram o sentido do signo linguístico, antes ratificaram

\footnotetext{
7 Os sinais foram analisados no ELAN.

8 Os sinais foram analisados no ELAN.
} 
as possibilidades de construções fonológicas por cada comunidade de fala. Adotamos os termos Mão DOMINANTE (M1) para representar aquela cuja configuração apresenta movimento e Mão de Apoio (M2) para aquela que atua como base da mão dominante. Apresentamos a descrição dos sinais: mar e sal.

Quadro 1 - Descrição dos parâmetros fonológicos do sinal MAR.

\begin{tabular}{|c|c|c|}
\hline PARÂMETROS & JOÃO PESSOA & RECIFE \\
\hline $\begin{array}{l}\text { Configuração } \\
\text { de mãos }\end{array}$ & $\begin{array}{l}\text { M1 - CM "38" } \\
\text { M1 e M2 - CM "61" }\end{array}$ & M1 - CM "61" \\
\hline Locação & $\begin{array}{l}\text { M1 - CM "38" - rosto } \\
\text { M1 e M2 - CM "61" - espaço neutro }\end{array}$ & M1 - CM "61" espaço neutro \\
\hline Movimento & $\begin{array}{l}\text { M1 - CM "38" tipo - semicircular } \\
\text { direção - bidirecional para esquerda e } \\
\text { direita } \\
\text { M2 - CM "61" movimento interno dos } \\
\text { dedos } \\
\text { Interação - afastamento }\end{array}$ & $\begin{array}{l}\text { M1 - CM "61" movimento } \\
\text { sinuoso }\end{array}$ \\
\hline Orientação & $\begin{array}{l}\text { M1 - CM "38"para o lado } \\
\text { M1 e M2 - CM "61" - para baixo }\end{array}$ & M1 - CM "61" para baixo \\
\hline ENM & Articulação dos lábios - semiabertos & $\begin{array}{l}\text { Lábios projetados e olhos } \\
\text { levemente franzidos }\end{array}$ \\
\hline
\end{tabular}

Fonte: Dados da pesquisa.

O sinal MAR apresentou variação nos seguintes parâmetros:

Movimento: neste sinal, tanto o sujeito $A^{9}$ quanto o sujeito $B^{10}$ realizaram o movimento Tipo - Contorno - Semicircular referente à CM 38. O sujeito B sinalizou a CM "61" com uma mão utilizando o movimento sinuoso. 0 sujeito A realizou a CM "61" com duas mãos, neste caso, observou-se o uso do movimento de interação - afastamento.

Expressão não manual: o sujeito A produziu a ENMs "lábios semiabertos" para a configuração $C M$ " 61 " realizada pela $M 1$. O sujeito B apresentou "lábios projetados e olhos levemente franzidos".

\footnotetext{
${ }^{9}$ Sinais utilizados pela comunidade surda em João Pessoa.
}

10 Sinais utilizados pela comunidade surda em Recife. 
O sinal MAR apresentou variações fonológicas em apenas dois parâmetros. O uso de ambas as mãos na sinalização do sujeito $A$ exigiu 0 emprego dos movimentos de afastamento simultâneo. Isto não foi necessário na sinalização do sujeito $B$, pois sinalizou MAR com apenas uma mão. A sinalização com duas mãos enfatiza a extensão do sinal MAR. Quanto à ENM, o sujeito B apresentou maior ênfase ao projetar os lábios e franzir os olhos levemente do que o sujeito $A$, quando articulou os lábios de forma semiaberta.

Quadro 2 - Descrição dos parâmetros fonológicos do sinal SAL

\begin{tabular}{lll}
\hline PARÂMETROS & JOÃO PESSOA & RECIFE \\
\hline Configuração de mãos & M1 CM "8" & "M1 CM "61" \\
& M1 CM "1" & \\
& M1 CM "38" & \\
\hline Locação & Espaço neutro & Lábios \\
\hline Movimento & Tipo - Contorno - Retilíneo & Contato - Toque \\
& Direcionalidade - & Interação - afastamento \\
& Unidirecional para direita & Movimento semicircular \\
\hline Orientação & Para fora & Bidirecional para dentro e para \\
& & fora \\
\hline ENM & Articulação dos lábios da & Olhos franzidos \\
& palavra sal & Lábios semiabertos \\
\hline
\end{tabular}

Fonte: Dados da pesquisa.

A análise fonológica do sinal SAL identificou variação fonológica nos cinco parâmetros.

Configuração de mãos: o sujeito A sinalizou as configurações "8", "1" e "38" com a mão dominante, realizando soletração rítmica. Essas configurações são utilizadas para datilologia da palavra SAL. O sujeito B utiliza a CM "61".

Locação: o sujeito A localiza o sinal no espaço neutro. Já o sujeito B localiza o sinal nos lábios, relacionando o conceito de sal ao paladar.

Movimento: o sujeito A executa a soletração rítmica com movimento retilíneo unidirecional. A sinalização do sujeito $B$ utiliza os movimentos "contato - toque", "interação - afastamento" e "movimento semicircular". 
Orientação: o sujeito A orientou as configurações "8", "1" e "38” para fora, enquanto o sujeito B orientou a CM "61" bidirecional de dentro para fora.

ENM: sujeito $A$, articulação labial da palavra sal. Sujeito $B$, olhos franzidos e lábios semiabertos.

Neste signo, encontramos uma variação referente à datilologia "SAL" pelo sinalizador A que realiza a soletração rítmica da palavra "sal" em português. É considerado como empréstimo linguístico. O sinalizador de Recife utiliza a CM 61 localizando-a na língua para referir-se ao paladar, e por consequência ao sabor do sal. São duas possibilidades de construção de sinais, uma por empréstimo linguístico e outra por uma CM aliada ao significado semântico.

\section{Algumas conclusões}

Os dados analisados demonstram que, embora os parâmetros fonológicos tenham apresentado variação, não existiu prejuízo quanto ao sentido. Quando Labov, em suas análises, considerou aspectos semelhantes a esses, estabeleceu um conceito micro para as interações sociais, baseado tanto no emprego de regras gramaticais quanto no uso da língua pelos falantes. Surge, assim, o conceito comunidade de fala que privilegia o grupo de falantes enquanto objeto de pesquisa, por acreditar que as produções de uma comunidade representam variáveis do processo de circulação e emergência das línguas.

Baseando-se nesse conceito, esta pesquisa se propôs a investigar os parâmetros fonológicos variacionais da Libras nas comunidades de fala de João Pessoa e Recife. A descrição sobre a língua de sinais apresentada neste trabalho consistiu em descrever as principais variações fonológicas.

A utilização do Eudico Linguistic Annotator (ELAN) para a descrição das variações fonológicas propiciou a identificação minuciosa dos parâmetros fonológicos. A sua identificação resultou em um quadro descritivo para cada um dos dez termos selecionados das categorias PLANTA e NATUREZA, e um gráfico geral apresentando a variação de cada parâmetro. Os parâmetros fonológicos que apresentaram maior variação foram a configuração de mãos e o movimento. Esses parâmetros estão destinados à relação descritiva e 
funcional dos sinais selecionados para análise. Houve variação de configuração de mãos em 08 dos 10 sinais descritos e variação de movimento em todos os sinais.

Embora o índice de variação dos parâmetros configuração de mãos e movimento tenha sido alto, todos os termos apresentaram construções fonológicas, morfológicas e semânticas. A constatação dessas variáveis comprova mais uma característica comum entre as línguas de sinais e as línguas orais. Ainda existe a necessidade de mais estudos linguísticos que proporcionem uma maior análise sobre a Libras em território nacional para o aprofundamento dos estudos sociolinguísticos. Porém, esperamos ter dado uma contribuição para um ensino da língua de sinais que perpasse pela variação linguística.

\section{Referências}

ANDRADE, W. T. L. Variação fonológica da LIBRAS: um estudo sociolinguístico de comunidades surdas da Paraíba. 2013. 137 f. Tese (Doutorado em Linguística) - Universidade Federal da Paraíba, João Pessoa, 2013.

BELINE, R. A variação linguística. In: FIORIN, J. L. (org.). Introdução à linguística. 6. ed. São Paulo: Contexto, 2011.

CAVALCANTE, M. C. B. Sociolinguística. In: FARIA, E. M. B.; CAVALCANTE, M. C. B. (orgs.). Língua portuguesa: teorias e práticas. vol. 3. João Pessoa: Editora Universitária, 2011.

DELGADO, I. C. Uma análise estilística da Língua Brasileira de Sinais: variações de seu uso no processo interativo. 2012. $190 \mathrm{f}$. Tese (Doutorado em Linguística) - Universidade Federal da Paraíba, João Pessoa, 2012.

FARIA, E. M. B. Aquisição da linguagem. In: FARIA, E. M. B.; ASSIS, M. C. (orgs.). Língua portuguesa: teorias e práticas. vol. 6. João Pessoa: Editora Universitária da UFPB, 2012.

FERNANDES, S.; STROBEL, K. L. Aspectos linguísticos da língua brasileira de sinais. Curitiba: SEED, SUED, DEE, 1998.

FERREIRA-BRITO, Lucinda. Por uma gramática de Língua de Sinais. Rio de Janeiro: Tempo Brasileiro; UFRJ, 2010.

FIORIN, J. L. A linguagem em uso. In: FIORIN, J. L. (org.). Introdução à linguística. 6. ed. São Paulo: Contexto, 2011. 
LABOV, W. Padrões sociolinguísticos. São Paulo: Parábola Editorial, 2008.

LEITE, T. A. A segmentação da língua de sinais brasileira (libras): um estudo linguístico descritivo a partir da conversação espontânea entre surdos. 2008. 280 f. Tese (Doutorado em Estudos Linguísticos e Literários em Inglês) Faculdade de Filosofia, Letras e Ciências Humanas, Universidade de São Paulo, São Paulo, 2008.

LILLO-MARTIN, D. Estudos de aquisição de línguas de sinais: passado, presente e futuro. In: QUADROS, R. M.; VASCONCELOS, M. L. B. Questões teóricas de pesquisas em línguas de sinais. Florianópolis: Arara Azul, 2006.

NASCIMENTO, S. P. F. Representações lexicais da Língua de Sinais Brasileira: uma proposta lexicográfica. 2009. 290 f. Tese (Doutorado em Linguística) - Universidade de Brasília, Brasília, 2009.

QUADROS, R. M.; KARNOPP, L. B. Língua de sinais: estudos linguísticos. Porto Alegre: ARTMED, 2004.

SEVERO, C. G. A comunidade de fala na sociolinguística laboviana: algumas reflexões. Revista Voz das Letras, Concórdia, Santa Catarina, Universidade do Contestado, n. 9, I semestre, 2008. Disponível em:

http://www.nead.uncnet.br/2009/revistas/letras/9/92.pdf. Acesso em: 02 ago. 2013.

STROBEL, K. As imagens do outro sobre a cultura surda. Florianópolis: Editora da UFSC, 2008.

WEINREICH, U.; LABOV, W. HERZOG, M. Fundamentos empíricos para uma teoria da mudança linguística. São Paulo: Parábola, 2006 [1968].

XAVIER, A. N. Descrição fonético-fonológica dos sinais da Língua de Sinais Brasileira (Libras). 2006. Dissertação (Mestrado em Linguística) - Universidade de São Paulo, São Paulo, 2006. Disponível em: http://www.culturasorda.eu/resources/Tesis_+Xavier_2006.pdf. Acesso em: 13 nov. 2012. 